\title{
Comments on the ISRM Suggested Method "A Failure Criterion for Rocks Based on True Triaxial Testing"
}

\author{
Marek Kwaśniewski
}

Received: 25 February 2013/Accepted: 22 March 2013/Published online: 16 April 2013

(C) The Author(s) 2013. This article is published with open access at Springerlink.com

Having read the ISRM Suggested Method "A failure criterion for rocks based on true triaxial testing" [3], I believe that it can be improved in several places. My comments and suggestions for modification or change are as follows:

1. When writing about the linear version of Mogi's failure criterion (Eq. 2) in Section 3, the authors did not mention that formulae which relate the parameters $a$ and $b$ to cohesion, angle of internal friction and uniaxial compressive strength (Eqs. 3a-4b) are valid only for the axisymmetric state of stress. This omission may be misleading to readers who are not experts on the failure criteria for rocks. In order to avoid possible misinterpretations or misunderstandings, it would be better to state expressis verbis that Eqs. (3a)-(4b) apply only in the case where $\sigma_{2}=\sigma_{3}$ and $\tau_{\text {oct }}$ in Eq. (2) is equal to $\frac{\sqrt{2}}{3}\left(\sigma_{1}-\sigma_{3}\right)$ (for details see 1 ). Consequently, the remarks on the dependence of the angle of internal friction on intermediate principal stress, given in the closing paragraph of Section 3, although true, become inappropriate and unnecessary in that particular place.

2. In the paragraph which starts with "Some 25 years later, Haimson and Chang (2000) tested the strength and deformability of Westerly granite..." in Section 2, the authors write: "They derived an experiment-based true triaxial failure criterion for the granite which was similar to Mogi's." I find this statement somewhat imprecise. In my opinion, it should read as follows: "When looking for a failure criterion capable of fitting

M. Kwaśniewski $(\square)$

Faculty of Mining and Geology, Silesian University

of Technology, Gliwice, Poland

e-mail: marek.kwasniewski@polsl.pl their true triaxial compression test results, they found that their data follow the same relationship between $\tau_{\text {oct }}$ and $\sigma_{m, 2}$ as that which was originally disclosed by Mogi."

3. When commenting on Mogi's power-law failure criterion at the beginning of Section 3, the authors write that "... there is no obvious direct correlation between the two constants [A and n] and known rock mechanical properties." This statement is inaccurate. In fact, the following relationship occurs:

$A=\frac{2^{n+0.5} C_{\mathrm{o}}^{1-n}}{3}$

where $C_{\mathrm{o}}$ is the uniaxial compressive strength.

4. The observation formulated in the first paragraph of Section 4 that: "All test results plotted in the form of $\tau_{\text {oct }}$ as a function of $\sigma_{m, 2}$ are best fitted by a power function..." is disputable. As I showed in a review paper written for the International Workshop on the True Triaxial Testing of Rocks, Beijing, October 17, 2011 [5], it is not always the case that Mogi's powerlaw criterion gives the best fit to the experimental data. Depending on the rock type and other factors like, for example, the range of the values of $\sigma_{2}$ and $\sigma_{3}$, other criteria (e.g. linear Mogi criterion or Zhang \& Zhu criterion) may be more suitable to describe the relationship between $\tau_{\text {oct }}$ and $\sigma_{\mathrm{m}, 2}$ at strength failure.

5. The reservation stated in Section 4 that a practical limitation of the Mogi criterion $\left(\tau_{\text {oct }}=\mathrm{f}\left(\sigma_{\mathrm{m}, 2}\right)\right)$ is that it requires the use of a true triaxial testing apparatus is disputable as well. It has already been well established experimentally that this criterion fits empirical data from the conventional triaxial compression (CTC) tests and from true triaxial compression (TTC) tests equally well (for example, see Figs. 1, 2 where the results of 
CTC and TTC tests carried out by 7, 8 and 2 on samples of Dunham dolomite and Westerly granite, respectively, were fitted, separately, using the same Mogi's power-law failure criterion). Therefore, it is not absolutely necessary to carry out the TTC tests in order to determine the values of parameters $A$ and $n$ (power-law criterion) or $a$ and $b$ (linear criterion). The values of these parameters can be determined based on the results of much simpler CTC tests. Then, after being incorporated into Mogi's criterion, they may serve to assess the ultimate strength of rocks under both axisymmetric and asymmetric stress conditions. Note, how remarkably high the goodness of fit is and how close to each other are the values of the parameter $n$ estimated as a result of fitting, separately, the CTC test data (Figs. 1a, 2a), the TTC test data (Figs. 1b, 2b) and the combined data sets from the CTC and the TTC tests (Figs. 1c, 2c).

6. If the above mentioned feature of the Mogi failure criterion is taken into account, the title of the Suggested Method "A Failure of Criterion for Rocks Based on True Triaxial Testing" becomes somewhat inappropriate. I would, therefore, like to suggest that it be modified to read as follows: "The Mogi Failure Criterion". The proposed modification seems to be justified the more as the titles of all other ISRM Suggested Methods for rock failure criteria include the names of their authors.

7. When discussing the difference in the ultimate strength of rocks under $\sigma_{2}=\sigma_{3}$ and $\sigma_{2}=\sigma_{1}$ conditions in Sect. 4 , the Authors refer only to papers by 9 and 4 . Unfortunately, they seem not to have noticed the work by 6, who was the first to conduct the most carefully designed and highly accurate experimental studies on the effect of intermediate principal stress, testing solid cylindrical samples of Westerly granite, Dunham dolomite and Solnhofen limestone under conventional triaxial compression and reduced triaxial extension conditions. Moreover, the data obtained by Handin, Heard and Magouirk are of a rather poor quality. When examined closely, they do not provide clear evidence of the effect of $\sigma_{2}$ on the strength of rocks (see 8, pp 53-54).

8. I am of the opinion that the list of references in the Suggested Method should be extended by adding Mogi's book on experimental rock mechanics [8] in which the results of all true triaxial testing experiments conducted by Mogi in his laboratory at the University of Tokyo in the years 1969-1978 are presented and discussed in great detail. In particular, Chapter 3 in Mogi's book is still the most comprehensive source of information on almost all aspects of the strength behavior of rocks under true triaxial compression conditions. (a) Dunham dolomite (2); $\sigma_{2}=\sigma_{3}$ test conditions

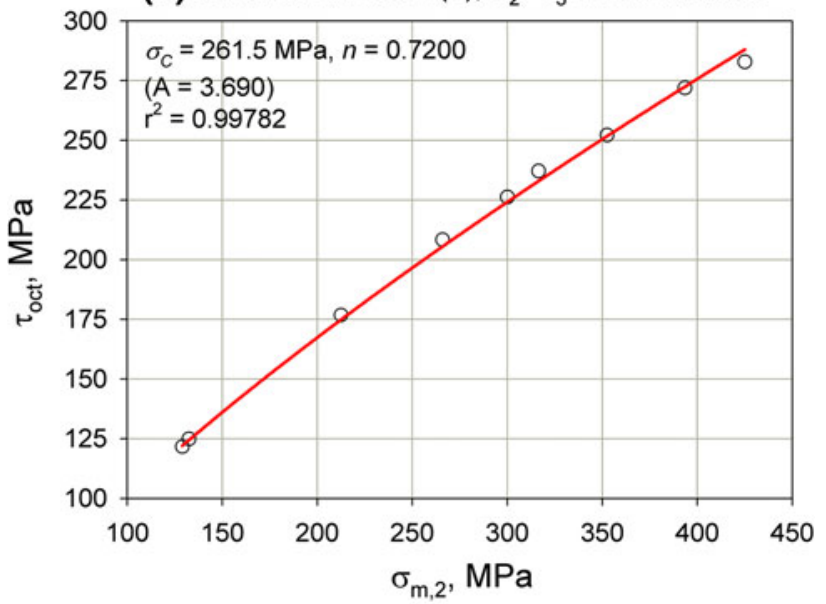

(b) Dunham dolomite (2); $\sigma_{2}>\sigma_{3}$ test conditions

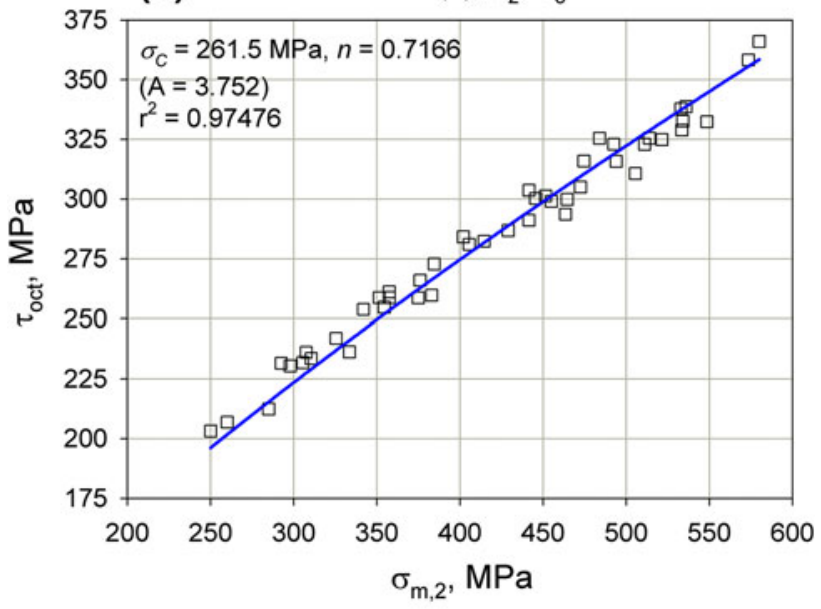

(c) Dunham dolomite (2); $\sigma_{2}=\sigma_{3} \& \sigma_{2}>\sigma_{3}$ test conditions

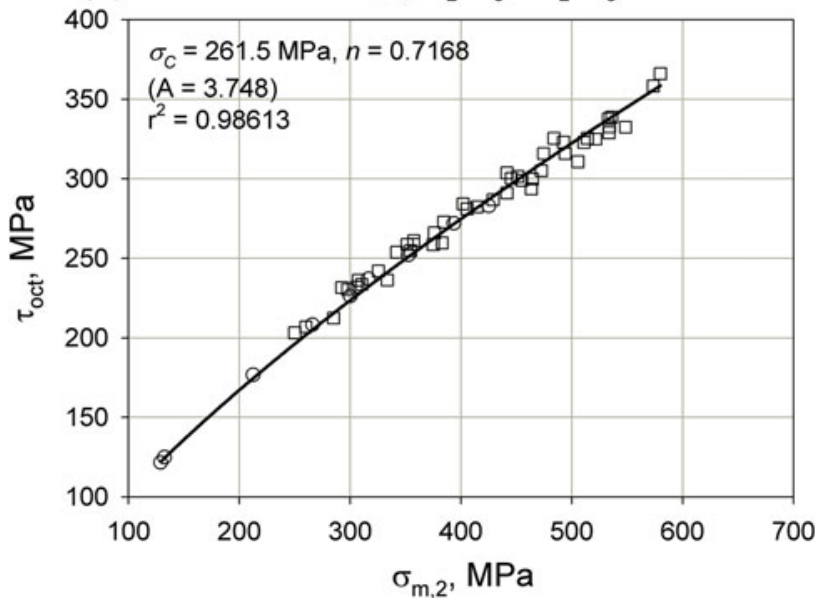

Fig. 1 Results of triaxial tests carried out by 7, 8 on samples of Dunham dolomite, fitted using Mogi's power-law failure criterion: a, data from triaxial compression tests where $\sigma_{2}=\sigma_{3}$ (axisymmetric stress conditions); b, data from true triaxial compression tests $\left(\sigma_{2} \neq \sigma_{3}\right) ; \mathbf{c}$, a and $\mathbf{b}$ data sets combined together 
(a) Westerly granite; $\sigma_{2}=\sigma_{3}$ test conditions

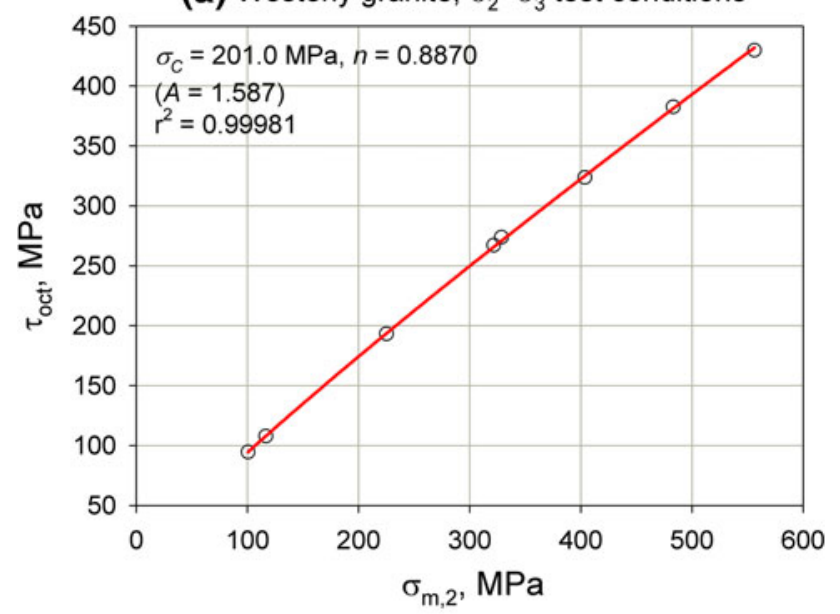

(b) Westerly granite; $\sigma_{2}>\sigma_{3}$ test conditions

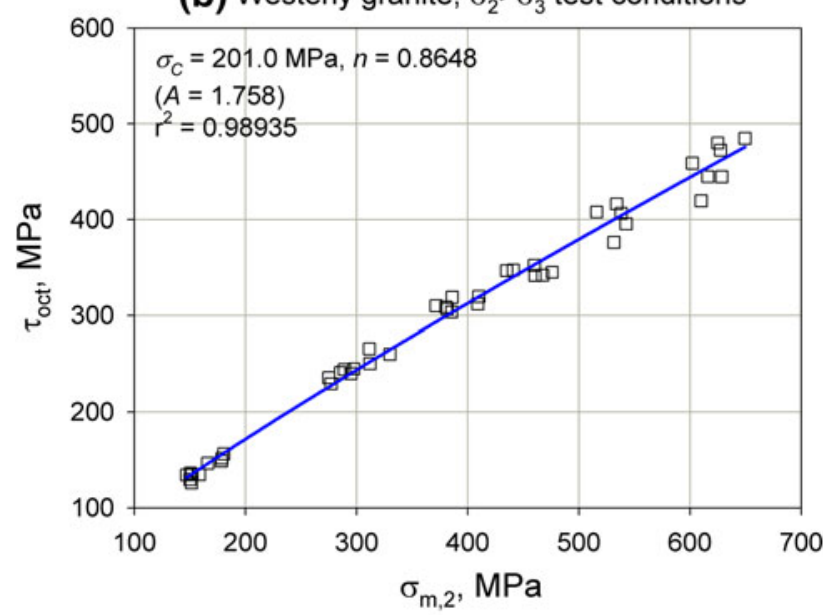

(c) Westerly granite; $\sigma_{2}=\sigma_{3} \& \sigma_{2}>\sigma_{3}$ test conditions

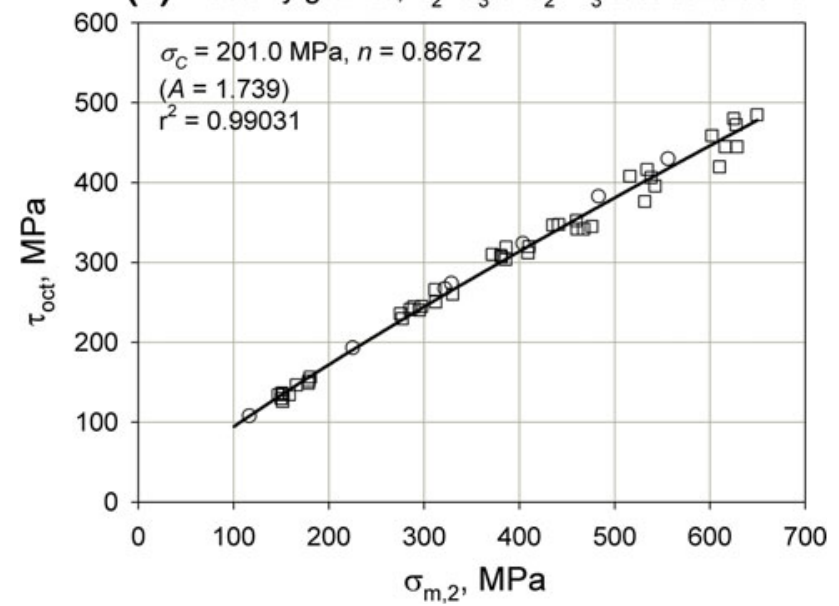

Fig. 2 Results of triaxial tests carried out by 2 on samples of Westerly granite, fitted using Mogi's power-law failure criterion: a data from triaxial compression tests where $\sigma_{2}=\sigma_{3}$ (axisymmetric stress conditions), b data from true triaxial compression tests $\left(\sigma_{2} \neq \sigma_{3}\right) ; \mathbf{c}$, $\mathbf{a}$ and $\mathbf{b}$ data sets combined together
9. The lists of symbols given at the beginning of the Suggested Method should be extended by adding $C_{o}$ (the uniaxial compressive strength) and $q(q=(1+\sin \phi) /$ $(1-\sin \phi))$.

Should the document discussed here be a regular paper, I would probably have refrained from commenting on it. However, the ISRM Suggested Methods are documents of a different nature; they offer suggestions and recommendations that are also meant for users who may not necessarily be familiar with the details of the particular subject. In this respect, the information provided in them should be as precise and accurate as possible. Of course, the shortcomings pointed out above are not of critical importance. However, it may be useful to correct them.

Open Access This article is distributed under the terms of the Creative Commons Attribution License which permits any use, distribution, and reproduction in any medium, provided the original author(s) and the source are credited.

\section{References}

1. Al-Ajmi AM, Zimmerman RW (2005) Relation between the Mogi and the Coulomb failure criteria. Int $J$ Rock Mech Min Sci 42:431-439

2. Chang C (2001) True triaxial strength and deformability of crystalline rocks. Ph. D. Thesis, University of Wisconsin, Madison

3. Chang C, Haimson B (2012) A failure criterion for rocks based on true triaxial testing. Rock Mech Rock Eng 45:1007-1010

4. Handin J, Heard HC, Magouirk JN (1967) Effects of the intermediate principal stress on the failure of limestone, dolomite, and glass at different temperatures and strain rates. J Geophys Res 72:611-640

5. Kwaśniewski M (2012) Mechanical behavior of rocks under true triaxial compression conditions-a review. In: Kwaśniewski M et al (eds) True triaxial testing of rocks. CRC Press/Balkema, Leiden, pp 99-138

6. Mogi K (1967) Effect of the intermediate principal stress on rock failure. J Geophys Res 72:5117-5131

7. Mogi K (1971) Effect of the triaxial stress systems on the failure of dolomite and limestone. Tectonophysics 11:111-127

8. Mogi K (2006) Experimental rock mechanics. Taylor \& Francis/ Balkema, Leiden

9. Murrell SAF (1963) A criterion for brittle fracture of rocks and concrete under triaxial stress, and the effect of pore pressure on the criterion. In: Fairhurst C (ed) Rock Mechanics (Proc. 5th Symp. Rock Mech., The University of Minnesota, 1962). Pergamon Press, New York, pp 563-577 